This is the final peer-reviewed accepted manuscript of:

Donati, M., Laroucau, K., Guerrini, A., Balboni, A., Salvatore, D., Catelli, E., Lupini, C., Levi, A., Di Francesco, A., 2018. Chlamydiosis in Backyard Chickens (Gallus gallus) in Italy. Vector-Borne and Zoonotic Diseases 18, 222-225.

The final published version is available online at: http://doi.org/10.1089/vbz.2017.2211

Rights / License:

The terms and conditions for the reuse of this version of the manuscript are specified in the publishing policy. For all terms of use and more information see the publisher's website.

This item was downloaded from IRIS Università di Bologna (https://cris.unibo.it/)

When citing, please refer to the published version. 


\section{Chlamydiosis in Backyard Chickens (Gallus gallus) in Italy}

2 Manuela Donati, ${ }^{1}$ Karine Laroucau, ${ }^{2}$ Alessandro Guerrini, ${ }^{3}$ Andrea Balboni, ${ }^{3}$ Daniela Salvatore, ${ }^{3}$

3 Elena Catelli, ${ }^{3}$ Caterina Lupini, ${ }^{3}$ Aurora Levi, ${ }^{1}$ and Antonietta Di Francesco ${ }^{3}$

$4{ }^{1}$ Department of Experimental, Diagnostic and Specialty Medicine, University of Bologna, Bologna, 5 Italy.

6 2University Paris-Est, Anses, Animal Health Laboratory, Bacterial Zoonoses Unit, Maisons-Alfort, 7 France.

$8{ }^{3}$ Department of Veterinary Medical Sciences, University of Bologna, Ozzano dell'Emilia 9 (Bologna), Italy.

11 Keywords: Chlamydia gallinacea, Chlamydia psittaci, chicken, epidemiology, PCR

13 Running title

14 Chlamydiosis in chickens

\section{Correspondence:}

17 A. Di Francesco. Department of Veterinary Medical Sciences, University of Bologna, Ozzano

18 dell'Emilia, Bologna, Italy.

19 Tel: +39 51 2097063; Fax: +39 512097039

20 E-mail: antoniet.difrancesco@ unibo.it

\section{Abstract}

22 Until recently, Chlamydia psittaci was considered to be the only etiological agent of avian 23 chlamydiosis, but two new avian species, Chlamydia gallinacea and Chlamydia avium, have 
recently been described in poultry and pigeons or psittacine birds, respectively. The aim of this study was to explore the occurrence of $C$. psittaci and $C$. gallinacea in backyard chickens in Italy. Cloacal swabs were taken from 160 asymptomatic chickens reared in 16 backyard farms. Samples were tested for $C$. psittaci and $C$. gallinacea by specific real-time polymerase chain reaction assays, with $24(15 \%)$ of the 160 chickens resulting positive for C. gallinacea. In order to attempt chlamydial isolation, new samples were obtained from two farms harboring a high prevalence (60\% and $70 \%$, respectively) of $C$. gallinacea-positive chickens. In total, eight $C$. gallinacea and one $C$. psittaci isolates were successfully recovered from 13 chickens. C. gallinacea was confirmed to be the endemic chlamydial species in chickens, with a high ompA intraspecies diversity. The presence of viable $C$. psittaci and $C$. gallinacea demonstrated by isolation from chickens in backyard farms poses a potential public health problem.

\section{Introduction}

Avian chlamydiosis is a bacterial disease of birds caused by members of the genus Chlamydia. Chlamydia psittaci has been the primary pathogenic chlamydial species identified in clinical infection, known as psittacosis, but at least two additional species, Chlamydia avium and Chlamydia gallinacea, have now been recognized (Sachse et al. 2014). Wild birds, pet birds and poultry are major reservoirs of $C$. psittaci. Depending on the virulence of the infecting strain and the species and age of the bird, $C$. psittaci infection can be subclinical or characterized by mild to severe respiratory, enteric and ocular symptoms (Andersen 1997). Zoonotic transmission mainly occurs through inhalation of an infectious aerosol or direct contact with contaminated feces or feathers, particularly in high-risk individuals, such as bird owners, veterinarians, bird breeders, pet shop staff, poultry, slaughterhouse and laboratory workers (Deschuyffeleer et al. 2012). In humans, clinical signs vary from a mild flu-like illness to severe atypical pneumonia. 
C. avium has been found in asymptomatic or sick pigeons but also in psittacines (Hölzer et

al. 2016). C. gallinacea was first identified in poultry flocks that had been linked to human chlamydiosis and it is suspected to be a zoonotic pathogen (Laroucau et al. 2009). Its virulence for birds is still unclear, although persistent infection has been linked to reduced body weight gain in broiler chickens (Guo et al. 2016).

In Italy, epidemiological studies on avian chlamydiosis have mostly been performed on wild birds such as pigeons (Magnino et al. 2009), collared doves (Donati et al. 2015) and corvids (Di Francesco et al. 2015). To our knowledge, no systematic investigations on chlamydiosis using highly specific diagnostic assays have been performed in poultry. The aim of this study was to explore the occurrence of $C$. psittaci and $C$. gallinacea in backyard chickens in Italy.

\section{Materials and Methods}

From March to June 2016, cloacal swabs were collected from 160 asymptomatic backyard chickens (Gallus gallus), reared in 16 farms located in six Italian regions (Table 1). The main races were Siciliana, Romagnola, Moroseta and Livorno, reared for ornamental purposes and/or selfconsumption of meat. In July 2016, 13 chickens from the two farms where the highest number of chickens tested positive were sampled to attempt chlamydial isolation, according to Donati et al. (2010).

Genomic DNA was extracted from the cloacal swabs and the chlamydia-positive cell cultures using the QIAamp DNA mini kit (Qiagen, Hilden, Germany) following the supplier's recommendations. DNA was screened by a Chlamydiaceae-specific real-time polymerase chain reaction (rt-PCR) targeting a region of the 23S rRNA gene conserved among all Chlamydiaceae (Ehricht et al. 2006). Samples with $C t$ values $<40$ were considered positive and reanalyzed by a $C$. 
psittaci-specific rt-PCR targeting the incA gene (Ménard et al. 2006) and C. gallinacea-specific rtPCR targeting the enoA gene (Laroucau et al. 2015).

The polymorphism of $C$. gallinacea in the backyard poultry studied was investigated by amplifying the ompA gene of $C$. gallinacea positive samples using the new primers CG3 (5'GGAGATTATGTTTTCGA-3') and CG4 (5'-CTTGCCATTCATGGTATT-3'). The primers targeted a fragment of approximately 600 base pairs, that included ompA variable domains (VDs) III-III (Kaltenboeck et al. 1993). C. gallinacea 08-1274/3 type strain was used as positive control. The PCR products were purified using a QIAquick PCR purification kit (Qiagen, Hilden, Germany) and both DNA strands were sequenced (Bio-Fab Research, Rome, Italy). The sequences were compared to each other and to the ompA sequence of the $C$. gallinacea $08-1274 / 3$ type strain using the BLAST server from the National Centre for Biotechnology Information (http://blast.ncbi.nlm.nih.gov/Blast.cgi). The nucleotide sequences found in the current study were submitted to the GenBank under accession numbers KY363892 to KY363923.

Then the C. gallinacea ompA sequences obtained in this study were edited, obtaining a gene fragment of 337-370 bp in length corresponding to nucleotides 210 to582 of the ompA gene of $C$. gallinacea type strain 08-1274/3 (GenBank accession number NZ AWUS01000004) including the ompA VDs I-II. The gene fragments were compared with other $C$. gallinacea corresponding sequences and phylogenetic relationships were evaluated.

\section{Results}

The results are reported in Table 1. Twenty-four of the 160 (15\%) samples collected in the first sampling were chlamydia-positive by $23 \mathrm{~S}$ rt-PCR. All the chlamydia-positive samples reacted positively to enoA-based rt-PCR for $C$. gallinacea. In the second sampling, nine chlamydial isolates were successfully obtained and identified as $C$. gallinacea $(\mathrm{n}=8)$ and $C$. psittaci $(\mathrm{n}=1)$ by the 
specific rt-PCRs. The 32 C. gallinacea ompA nucleotide sequences from field samples and isolates showed $83-100 \%$ similarity between them and $86-96 \%$ to the corresponding sequence of the 08 1274/3 C. gallinacea type strain. Nucleotide alignment distinguished the 32 C. gallinacea ompA sequences in 12 different ompA types (01-12). Phylogenetic comparison showed that some ompA types were closely related to some $C$. gallinacea ompA sequences from France or Asia (Figure 1). Some ompA types were highlighted in geographically distant backyard farms and several ompA types were highlighted in the same farm (Table 1).

\section{Discussion}

The present study detected C. gallinacea in $100 \%$ of the PCR chlamydia-positive chickens and in $89 \%$ of the chlamydial isolates. These results are consistent with those of previous reports suggesting that C. gallinacea is the endemic chlamydial species in chickens (Zocevic et al. 2012, Hulin et al. 2015, Guo et al. 2016, Li et al. 2017). The flocks examined were very similar in terms of zootechnical characteristics (free-range farms) and chicken races (Mediterranean light chicken breeds). The high chlamydia prevalence $(60 \%$ and $70 \%)$ observed in two flocks, compared with others, could be explained by the higher chicken turnover in these two farms. Sequence analysis of the C. gallinacea ompA gene fragments confirmed the high intraspecies diversity previously reported (Guo et al. 2016, Li et al. 2017), although the value of phylogenetic comparison based on partial gene sequences of ompA is limited ( $\mathrm{Li}$ et al. 2017). The presence of the same ompA type in different farms, as well as several ompA types in the same farm and the close relationship of some C. gallinacea strains with European or Asiatic strains are not surprising considering the features of the farms tested, which commonly introduce animals from Italian farms and from European or extra-European countries, and participate in Italian or foreign exhibitions. 
Nine chlamydial isolates were obtained, eight of which identified as C. gallinacean and one

as $C$. psittaci. To our knowledge, this is the first isolation of $C$. gallinacea in Italy. The detection of

121 viable bacteria confirmed the results of the PCR assays on chlamydia circulation in the tested farms, raising a potential public health problem. Whereas the principles and practices of on-farm biosecurity may be familiar to commercial farmers, hobbyists and backyard farmers may not be aware of the steps required to keep infectious diseases out of their flock and prevent their spread. Unlike $C$. psittaci, the zoonotic potential of $C$. gallinacea has yet to be investigated. In a previous study (Laroucau et al. 2009), three workers at a French slaughterhouse who had handled $C$. gallinacea-infected chickens showed signs of atypical pneumonia, even though previous exposure of these individuals to $C$. psittaci cannot be ruled out. Until recently, $C$. psittaci was considered the only agent of avian chlamydiosis. In the past, mainly before the common use of molecular assays, the diagnosis of some human cases of chlamydiosis could have stopped at genus level, disregarding other potential etiological agents. Taking into account the complex etiology of avian chlamydiosis be systematically used both in birds and in humans to explore the potential zoonotic role of this new chlamydial species.

\section{Conflict of interest statement}

The authors of this paper do not have personal or financial relationships with people or organizations that could inappropriately influence the content of the paper.

139 References

140 Andersen AA. Two new serovars of Chlamydia psittaci from North American birds. J Vet Diagn Invest 1997; 9:159-164. 
Deschuyffeleer TP, Tyberghien LF, Dickx VL, Geens T, et al. Risk assessment and management of Chlamydia psittaci in poultry processing plants. Ann Occup Hyg 2012; 56:340-349.

Di Francesco A, Donati M, Laroucau K, Balboni A, et al. Chlamydiae in corvids. Vet Rec 2015; 177:466.

Donati M, Di Francesco A, D'Antuono A, Delucca F, et al. In vitro activities of several antimicrobial agents against recently isolated and genotyped Chlamydia trachomatis urogenital serovars D through K. Antimicrob Agents Chemother 2010; 54:5379-5380.

Donati M, Laroucau K, Delogu M, Vorimore F, et al. Chlamydia psittaci in Eurasian Collared Doves (Streptopelia decaocto) in Italy. J Wildl Dis 2015; 51:214-217.

Ehricht R, Slickers P, Goellne S, Hotzel H, et al. Optimized DNA microarray assay allows detection and genotyping of single PCR-amplifiable target copies. Mol Cell Probes 2006; 20:60-63.

Guo W, Li J, Kaltenboeck B, Gong J, et al. Chlamydia gallinacea, not C. psittaci, is the endemic chlamydial species in chicken (Gallus gallus). Sci Rep 2016; 6:19638.

Hölzer M, Laroucau K, Creasy HH, Ott S, et al. Whole-Genome Sequence of Chlamydia gallinacea Type Strain 08-1274/3. Genome Announc 2016:4, e00708-16.

Hulin V, Oger S, Vorimore F, Aaziz R, et al. Host preference and zoonotic potential of Chlamydia psittaci and C. gallinacea in poultry. Pathog Dis 2015; 73:1-11.

Kaltenboeck B, Kousoulas KG, Storz J. Structures of and allelic diversity and relationships among the major outer membrane protein $($ ompA) genes of the four chlamydial species. J. Bacteriol. 1993; 175:487-502.

Laroucau K, Vorimore F, Aaziz R, Bernd A, et al. Isolation of a new chlamydial agent from infected domestic poultry coincided with cases of atypical pneumonia among slaughterhouse workers in France. Infect Genet Evol 2009; 9:1240-1247.

Laroucau K, Aaziz R, Meurice L, Servas V, et al. Outbreak of psittacosis in a group of women exposed to Chlamydia psittaci-infected chickens. Euro Surveill 2015; 20: pii: 21155. 
Li L, Luther M, Macklin K, Pugh D, et al. Chlamydia gallinacea: a widespread emerging Chlamydia agent with zoonotic potential in backyard poultry. Epidemiol Infect 2017; 3:1-3.

Magnino S, Haag-Wackernagel D, Geigenfeind I, Helmecke S, et al. Chlamydial infections in feral pigeons in Europe: Review of data and focus on public health implications. Vet Microbiol 2009, 135:54-67.

Ménard A, Clerc M, Subtil A, Megraud F, et al. Development of a real-time PCR for the detection of Chlamydia psittaci. J Med Microbiol 2006; 55:471-473.

Sachse K, Laroucau K, Riege K, Wehner S, et al. Evidence for the existence of two new members of the family Chlamydiaceae and proposal of Chlamydia avium sp. nov. and Chlamydia gallinacea sp. nov. Syst Appl Microbiol 2014; 37:79-88.

Zocevic A, Vorimore F, Marhold C, Horvatek D, et al. Molecular characterization of atypical Chlamydia and evidence of their dissemination in different European and Asian chicken flocks by specific real-time PCR. Environ Microbiol 2012; 14:2212-2222. 
195 Figure 1. Phylogenetic comparison of Chlamydia gallinacea from backyard poultry in the present 196 study.

197 Phylogenetic relationships among the Chlamydia gallinacea ompA variable domains I-II obtained 198 in this study and other C. gallinacea corresponding sequences from poultry in France and China 199 were evaluated using MEGA 6.0. A pylogenetic tree was constructed by the neighbor-joining 200 method using the Tamura 3-parameter model with gamma distribution. A reference sequence of 201 Chlamydia psittaci (GenBank accession number CP003790) was used as outgroup. Bootstrap 202 values were determined by 1000 replicates to assess the confidence level of each branch pattern and 203 values $\geq 60 \%$ were reported. OmpA sequences obtained in this study are shown in bold type. 
Table 1. Information and results on investigated backyard chicken farms.

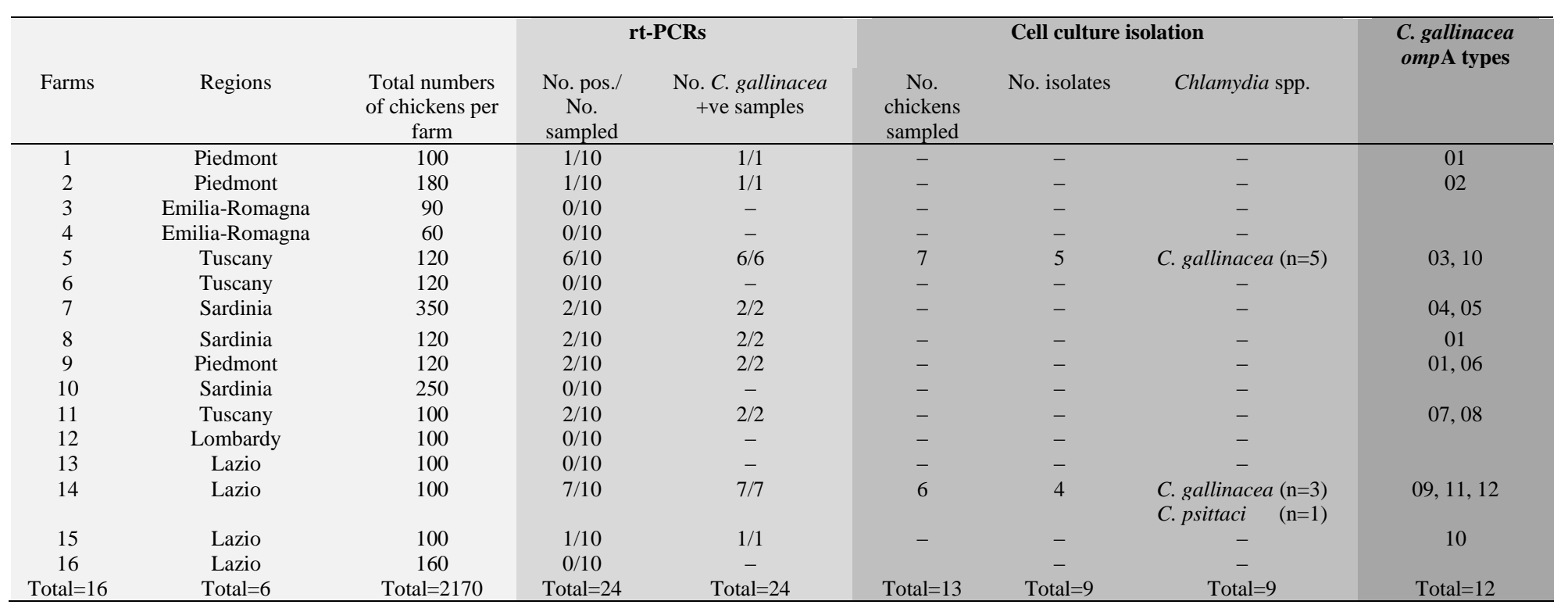

